\title{
EVALUATION OF MILD STEEL CORROSION AT DIFFERENT TEMPERATURES BY USING ELECTROCHEMICAL NOISE ANALYSIS (EN) AND ELECTROCHEMICAL IMPEDANCE SPECTRSCOPY (EIS).
}

\author{
A. M. NAGIUB \\ Chemistry Department, Faculty of Science, Al-Azhar University, Assiut 71524- \\ Egypt. \\ E-mail: nagiub@mailer.eun.eg Fax:002-088-2325436
}

\begin{abstract}
The influence of different temperatures on the corrosion of mild steel (MS) exposed to artificial seawater (AS) has been studied using the techniques of electrochemical noise (EN) and electrochemical impedance spectroscopy (EIS) at different temperatures. Comparisons have been made with results obtained by EIS and EN. Good agreement was observed between the noise resistances $\left(\mathrm{R}_{\mathrm{n}}\right)$ derived from the analysis of $\mathrm{EN}$ in the time domain and polarization resistance $\left(\mathrm{R}_{\mathrm{p}}\right)$ obtained from EIS. Analysis of EN data demonstrated the importance of removing drifts in the potential and current fluctuations during the measurements periods.
\end{abstract}

Keywords: mild steel, electrochemical noise, impedance, artificial seawater, temperatures

\section{Introduction}

Corrosion of steel immersed in seawater is influenced by the interaction of several factors including temperature, salinity, dissolved oxygen, $\mathrm{pH}$, carbon content and hydrostatic pressure. In general, when corrosion is controlled by diffusion of oxygen, the corrosion rates approximately doubles for every $30^{\circ} \mathrm{C}$ rise in temperature. However further increase of temperature may lead to a falling in corrosion rates due to increase of oxygen escaping tendency. In addition, it was reported that heated seawater might deposit a protective scale on the steel surface leading to a decrease in corrosion rate. In general, the process of corrosion of mild steel in seawater comprises two electrochemical reactions, anodic reaction corresponding to the dissolution of steel and cathodic one, which corresponds to reduction of oxygen [1-8].

Electrochemical noise is a general term for the random fluctuations in current or potential, which occur as an electrochemical process proceeds. There are many advantages of EN technique as compared with the other electrochemical techniques 
making it very popular, of these, the low cost of the equipments, ease of data collections and also EN is considered to be a time saving technique (most experimental time ranged between few minutes to $1 / 2$ hour). The measurement of electrochemical noise (EN) for corrosion studies was first described by Iverson in 1968 [9]. At the same time Tyagai examined EN [10-11]. First studies on EN were carried out using only one working electrode, which consequently will not allow the measurement of corrosion rate. Eden et al introduced the use of cell with two identical working electrodes connected with a zero resistance ammeter (ZRA) so that it is possible to collect both the current and potential fluctuation simultaneously [12]. The use of two identical electrodes arrangement will allow the obtaining of the noise resistance $\left(R_{n}\right)$, which is defined as the ratio of the standard deviation of the voltage and current fluctuations. $R_{n}$ was compared to the polarization resistance $\left(R_{p}\right)$ and many attempts had been done to compare between $R_{n}$ and $R_{p}$ [13-15]. $R_{n}$ was found to be close to $R_{p}$ under certain conditions so that $R_{n}$ can be used to calculate the corrosion rate using Stern-Geary relationship [16].

Recently, the validity of statistical parameters such as localization index (LI), skewness and kurtosis and frequency parameters such as power spectral density (PSD) slopes and spectral noise resistance $\left(\mathrm{R}_{\mathrm{sn}}\right)$ obtained from analyzing the EN in the time and frequency domains have been discussed [17-19]. Theoretical and experimental analysis of the effects of trends in the potential and current noise fluctuations observed during measurement of EN data have been studied before [18]. It was found that the dc trend can affect the calculated values of the standard deviations of the potential and current fluctuations and $\mathrm{R}_{n}$ also PSD plots. [18]. The same findings were observed for brass exposed to $\mathrm{NaCl}$ with and without BTA. A good agreement was obtained between the noise plots and the impedance plots for brass exposed to $\mathrm{NaCl}$ with BTA after trend removal [19]. The present work aims to test the validity of electrochemical noise analysis in studying mild steel corrosion at different temperatures compared to electrochemical impedance spectroscopy.

\section{Experimental Approach}

\section{Material and solution.}

For each experiment, electrochemical measurements were carried out in a two identical electrode configuration cell (2E) with a saturated calomel reference electrode (SCE). The tested electrode was mild steel 1018 sheet (MS) with exposed

area of $1 \mathrm{~cm}^{2}$. All corrosion measurements were performed in artificial seawater 
(AS) $(\mathrm{pH}=7.5)$ [20]. Prior to corrosion testing MS samples were subjected to mechanical polishing up to 1200 silicon carbide paper then cleaned in acetone. All corrosion experiments were carried out for a duration varying between 2 hours and 72 hours at $20,40,60$, and $80^{\circ} \mathrm{C}$.

\section{Measurement methods}

Two different electrochemical techniques were used to evaluate the corrosion behavior of MS exposed to AS. EIS was performed with AutoCAD DSP device (ACM Instruments). A sinusoidal perturbation of $10 \mathrm{mV} \mathrm{rms} \mathrm{was} \mathrm{applied} \mathrm{at} \mathrm{the} \mathrm{cell}$ over the frequency range of $30 \mathrm{kHz}-0.005 \mathrm{~Hz}$. EIS was conducted immediately after EN using the same cell. EIS data fitting were performed using Boukamp's software (EQUIVCRT) [21]. EN was preformed in a set-up with electrochemical cell consisting of two identical MS electrodes with an exposed area of $1.0 \mathrm{~cm}^{2}$ for each electrode and a SCE as a reference electrode within a Faraday cage. An AutoCAD DSP device (ACM Instruments) was used to collect potential and current fluctuations simultaneously. Potential and current fluctuations were obtained, with a sampling rate of 2-point $\mathrm{s}^{-1}$ during a time period of 1024 seconds, which fixed the frequency range $(\Delta \mathrm{f})$ in region between $1 \mathrm{~Hz}$ and about $1 \mathrm{mHz}$. The instrument noise was tested and shown to be with no influence on the noise measurements. An external water thermostat has been used to maintain the desired temperature before starting the noise measurements, and then stopped heating during the noise measurements to avoid noise interference by the heating system. Each EN data was completed before starting the EIS measurements using the same cell to avoid any obvious perturbation. A polynomial trend removal method was performed to remove the direct current (DC) drift contained in the noise data. The analysis of EN data in time domain was developed using Mathcad PLUS 6 software.

\section{Results and Discussion.}

Time variations of the open circuit potential $\left(\mathrm{E}_{\mathrm{corr}}\right)$ for MS exposed to AS at different temperatures for a period of 72 hours are shown in Fig.1. For all systems, $\mathrm{E}_{\text {corr }}$ becomes more negative with time and reaches a steady state after about 24 hours, except for $\mathrm{MS}$ at $80^{\circ} \mathrm{C}$, where $\mathrm{E}_{\text {corr }}$ slightly increases with time. Time dependence curves of Fig. 1 indicated that $E_{\text {corr }}$ had values of about -700 to $-740 \mathrm{mV}$, for all cases after immersion period of a 24 hours 
No significant changes in $\mathrm{E}_{\text {corr }}$ values were observed at different temperatures. Such results may suggest that after about 24 hours the rust was completely formed and covered the entire surface of MS sheets, consequently $\mathrm{E}_{\text {corr }}$ remains almost unchanged. Visual inspection of the surface of electrodes after each type of experiments showed that rust completely covered the entire surface of MS samples.

Fig. 2 shows the bode plots obtained for MS exposed to AS at $40^{\circ} \mathrm{C}$. It is obvious that only one time constant was observed with a minimum of phase angle ranged between $-45^{\circ}$ to $-55^{\circ}$ and $R_{p}$ close to $10^{3} \mathrm{ohm}$. The frequency corresponding to that phase angle minimum (time constant) shifted to lower frequency region with increasing the exposure time. This shift indicates an increase in the capacitance value and impedance, which may suggest a decrease in corrosion rate with exposure time. This decrease may be attributed to the formation of a protective film over MS samples, which becomes thicker with time. Fig. 3 shows Bode plots for MS exposed to $\mathrm{AS}$ at $80^{\circ} \mathrm{C}$. Similar to Fig. 2 only one time constant was observed and the impedance slightly increased with increasing the exposure time (Fig.3).

As was expected lower impedance values were observed at higher temperatures. Nearly identical shapes of Bode plots for MS exposed to AS at different temperatures may suggest similar corrosion mechanism (Fig.2 and 3). In order to interpret the EIS results shown in Figs (2 and 3), the impedance response of the MS samples is approximated by an appropriate equivalent circuit (EC). The suggested EC is shown in Fig. 4 (a). It consists of a solution resistance, $R_{s}$ in series with a parallel circuit of a polarization resistance $\left(R_{p}\right)$ and constant phase element (CPE). In studies of corroding systems, many authors use CPE to model surface heterogeneity caused by many factors such as: adsorption of inhibitors, impurities, surface roughness, etc. [22-24]. In other words, CPE is most often used to describe the frequency dependence for the non-ideal capacitive behavior. The impedance of CPE elements is given by [25]:

$$
Z_{\mathrm{CPE}}=\left[\mathrm{Q}(\mathrm{j} \omega)^{\mathrm{n}}\right]^{-1},
$$

Where $\mathrm{j}$ is the imaginary number, $\mathrm{Q}$ is the frequency-independent real constant, $\omega=2 \pi \mathrm{f}$ is the angular frequency $(\mathrm{rad} / \mathrm{sec}), \mathrm{f}$ is the frequency of the applied signal and $\mathrm{n}$ is the CPE exponent which is also known as roughness factor or surface inhomogeneity [22-24,26-27]. $\mathrm{n}$ will be equal to 1 for ideal capacitor. Fig. 4 (b) shows a comparison between the experimental and fitted impedance data for MS exposed to AS for 1 day at $40^{\circ} \mathrm{C}$ and 
$60^{\circ} \mathrm{C}$, respectively. Excellent agreement between the fitted and experimental data was obtained indicating that the EC circuit shown in Fig. 4 (a) (one time constant model) is best describing the corrosion system in this study.

Table 1 shows the fit parameters for MS exposed to AS at different temperatures. It is clear from Table 2 that the highest $\mathrm{R}_{\mathrm{p}}$ values were observed at $20^{\circ} \mathrm{C}$. The lower values of $\mathrm{Q}$ of about $4 \times 10^{-4} \mathrm{ohm}^{-1} \mathrm{~s}^{\mathrm{n}}$ were obtained for MS at $20^{\circ} \mathrm{C}$ which may be attributed to the formation of a more protective film on the MS surface compared to MS exposed to AS at higher temperature [28]. The $\mathrm{n}$ values listed in Table 1 lies between 0.5 and 0.7 for all systems, indicating that the sample surface was slightly inhomogeneous, because it may be covered with the corrosion products of different thicknesses [29].

Table 1. Fit parameters for MS in AS at different temperatures.

\begin{tabular}{|c|c|c|c|c|c|}
\hline Temperature & $\begin{array}{c}\text { Immersion } \\
\text { time }\end{array}$ & $\mathrm{Rp}(\mathrm{ohm})$ & $\mathrm{Q}\left(\mathrm{ohm}^{-1} \mathrm{~s}^{\mathrm{n}}\right)$ & $\mathrm{n}$ & $\mathrm{Rs}(\mathrm{ohm})$ \\
\hline \multirow{4}{*}{$20^{\circ} \mathrm{C}$} & 2-hours & 2500 & 0.002666 & 0.583 & 32.63 \\
\cline { 2 - 6 } & 1-day & 2962 & 0.000869 & 0.5803 & 33.79 \\
\cline { 2 - 6 } & 2-days & 3272 & 0.000513 & 0.7186 & 29.46 \\
\cline { 2 - 6 } & 3-days & 3352 & 0.000499 & 0.7382 & 28.62 \\
\hline \multirow{4}{*}{$40^{\circ} \mathrm{C}$} & 2-hours & 1153 & 0.000625 & 0.6678 & 21.38 \\
\cline { 2 - 6 } & 1-day & 1062 & 0.000525 & 0.747 & 22.94 \\
\cline { 2 - 6 } & 2-days & 1225 & 0.00086 & 0.7459 & 20.53 \\
\cline { 2 - 6 } & 3-days & 1271 & 0.000987 & 0.7469 & 21.68 \\
\hline \multirow{3}{*}{$60^{\circ} \mathrm{C}$} & 2-hours & 868.9 & 0.001438 & 0.6586 & 18.23 \\
\cline { 2 - 6 } & 1-day & 917.4 & 0.001377 & 0.55 & 10.91 \\
\cline { 2 - 6 } & 3-days & 1022 & 0.001488 & 0.5638 & 11.1 \\
\hline \multirow{5}{*}{$80^{\circ} \mathrm{C}$} & 2-hours & 908.9 & 0.002095 & 0.5467 & 14.2 \\
\cline { 2 - 6 } & 1-day & 1443 & 0.005014 & 0.5521 & 16.45 \\
\cline { 2 - 6 } & 2-days & 1066 & 0.005449 & 0.5629 & 17.18 \\
\cline { 2 - 6 } & 3-days & 1200 & 0.00603 & 0.68 & 22.03 \\
\hline
\end{tabular}

Fig. 5 (a) illustrates the time dependence of $\mathrm{R}_{\mathrm{p}}$ for $\mathrm{MS}$ at different temperatures. The results in Fig.5 (a) clearly demonstrate that temperature accelerates the corrosion of MS as indicated by the decrease of $R_{p}$ values with the increase of temperature. The highest $R_{p}$ values were obtained at $20^{\circ} \mathrm{C}$ and a slight increase of $R_{p}$ values with time were observed which might be due to a thickening of a rust film. 
It was reported that the corrosion rates for steel exposed to water doubles for every $30{ }^{\circ} \mathrm{C}$ rise in temperature, which is in agreement with the results shown in Fig. 5 (a), where an obvious decrease in $\mathrm{R}_{\mathrm{p}}$ values were obtained at $40{ }^{\circ} \mathrm{C}$ and at higher temperatures compared to those obtained at $20^{\circ} \mathrm{C}[3]$.

No large differences were observed between $R_{p}$ values at temperatures higher than $20^{\circ} \mathrm{C}$, which may be attributed to the formation of a protective scale and/or loss of oxygen, where both actions tends to reduce corrosion attack. The time dependence of experimental $Q$ values is shown in Fig.5 (b). The lower $Q$ values are associated with the lower temperature, which also could be due to thickening of the oxide film over MS samples. In General $\mathrm{Q}$ values decreased according to the following order, $80^{\circ} \mathrm{C}>60^{\circ} \mathrm{C}>40^{\circ} \mathrm{C}>20^{\circ} \mathrm{C}$. Q values calculated after 2 hours were scattered and did not follow a specific pattern, which may be attributed to system instability (i.e. steady state potential is not reached). Higher Q values at higher temperature may be attributed to the porous and conductive nature of underlying deposits [30].

The potential and current fluctuations were recorded simultaneously as described in the experimental section. Figs. 6 (a) and 6(b) show the plots of the potential and current noise respectively for MS exposed to AS for 2 hours. It is clear that a large DC trend of about $30 \mathrm{mV}$ and $0.02 \mathrm{~mA}$ was recorded respectively during the period of potential and current noise recording (Figs. 6 (a) and 6 (b)). As described elsewhere the DC trend will affect the estimation of noise parameters calculated both in time and frequency domains. The presence of the trend can mask the shape of current and potential fluctuations and may also affect the slopes of PSD plots of the current and potential [18,31-32]. Accordingly, polynomial trend removal method was applied to remove the DC trends in this study. Potential and current fluctuations after removing the trend (de-trended data ) are shown in Figs 6 (a) and 6 (b).

Fig.7 shows the experimental EN data for MS exposed to AS at different temperatures and exposure times. Fig.7 indicates that the observed DC trend was not large (i.e., $2 \mathrm{mV}$ ) which is attributed to increase of $\mathrm{E}_{\text {corr }}$ stability with time (Fig.1). As can be seen the DC trend in Figs 6 (a) and 6 (b) follows a linear relation however, the trend did not follow a specific pattern in case of Fig 7.

It is obvious that a linear trend removal methods can be successfully applied for data shown in Figs 6 (a) and 6 (b) while it will be not a good removal tool if it is applied for data shown in Fig. 7. Consequently, Polynomial trend method is the 
preferred method in this study since the observed DC trend did not follow a specific pattern. It can be concluded that removing the trend should be carried out cautiously when the DC trends did not follow a specific pattern.

The DC trend was removed by taking the best-polynomial-fit line then subtracting this line from the raw EN data without removing the mean. Assuming that the potential and current fluctuations follow the time (t) relations;

$$
\begin{aligned}
& \mathrm{V}=\mathrm{V}_{0}+\mathrm{a}_{1} \mathrm{t}+. .+\mathrm{a}_{\mathrm{n}} \mathrm{t}^{\mathrm{n}}, \\
& \mathrm{I}=\mathrm{I}_{0}+\mathrm{b}_{1} \mathrm{t}+. .+\mathrm{b}_{\mathrm{n}} \mathrm{t}^{\mathrm{n}},
\end{aligned}
$$

where $a, a 1 \ldots a_{n}$ and $b, b 1, b 2, \ldots b_{n}$ are constants, $V_{0}$ and $I_{0}$ are the intercepts of voltage and current at $\mathrm{t}=0$, respectively. $\mathrm{n}$ is the polynomial degree, so that for $\mathrm{n}$ equals 1 , equation 2 and 3 becomes a linear relation. Accordingly, the trend removal method will become a linear method. As was described by Bertocci et. al., n will play an important role in de-trending treatments, so that the lowest frequency can be drastically attenuated if $n$ equals 5 or greater [33]. $n$ values used in this study usually ranged between 1-3 according to the shape of the noise data.

Electrochemical noise resistance $\left(\mathrm{R}_{\mathrm{n}}\right)$ is defined as the ratio of the standard deviation of the potential noise $\left(\sigma_{v}\right.$ to that of current noise $\left(\sigma_{i}\right) . \quad R_{n}$ is usually assumed to be related to $R_{p}$ and therefore often used to calculate corrosion rates [15]. Fig. 8 shows the time dependence of $R_{n}$ for $M S$ exposed to AS at different temperatures. In General, it can be seen that $R_{n}$ values slightly increase with increase of exposure time. Examination of $\mathrm{R}_{\mathrm{n}}$ showed that its values increased with increasing of temperatures in the following pattern, $20^{\circ} \mathrm{C}>40^{\circ} \mathrm{C} \geq 60^{\circ} \mathrm{C}>80^{\circ} \mathrm{C}$ except for 2 hours data. These results showed a good agreement with EIS data obtained in this study (Fig. 5 a).

It is possible to measure corrosion current from the knowledge of the SternGeary equation according to:

$$
\mathrm{I}_{\text {corr }}=\mathrm{B} / \mathrm{R}_{\mathrm{p}}
$$

Where $B$ is the Tafel coefficient and $R_{p}$ is the polarization resistance calculated from EIS. By assuming, that $R_{p}$ is equivalent to $R_{n}$ the corrosion current can be calculated from the knowledge of $R_{n}$ by replacing $R_{p}$ with $R_{n}$ in equation 4 . Fig. 9 presents the time dependence of $I_{\text {corr }}$ values calculated from the knowledge of both $R_{p}$ and $R_{n}$ at different temperatures. Generally, $I_{\text {corr }}$ increases with increasing temperature. $I_{\text {corr }}$ values obtained from $R_{n}$ were slightly higher than those obtained from $R_{p}$. These 
results may suggest that calculating corrosion rates with the aid of $R_{n}$ gives a good qualitative way concerning the corrosion behavior of MS exposed to AS. Fig.9 also shows that $I_{\text {corr }}$ is almost independent of time especially after immersion time of 24 hours, which is in agreement with $\mathrm{E}_{\text {corr }}$ behavior shown in Fig. [1].

\section{Summary and conclusions}

In this paper, the effect of different temperatures on the corrosion behavior of MS 1018 has been investigated using EN and EIS techniques. Analysis of EIS data showed the influence of different temperatures on the corrosion behavior of MS as indicated by the decreases of impedance with increasing of temperatures. The EN data were affected by drifts during the measurement period, which was removed using polynomial trend removal method. $R_{n}$ was calculated after analysis of EN data in the time domain and showed an agreement with $R_{p}$ obtained from EIS analysis. Finally, it could be concluded in general that EN measurements provided useful information about the corrosion of mild steel exposed to AS at different temperatures.

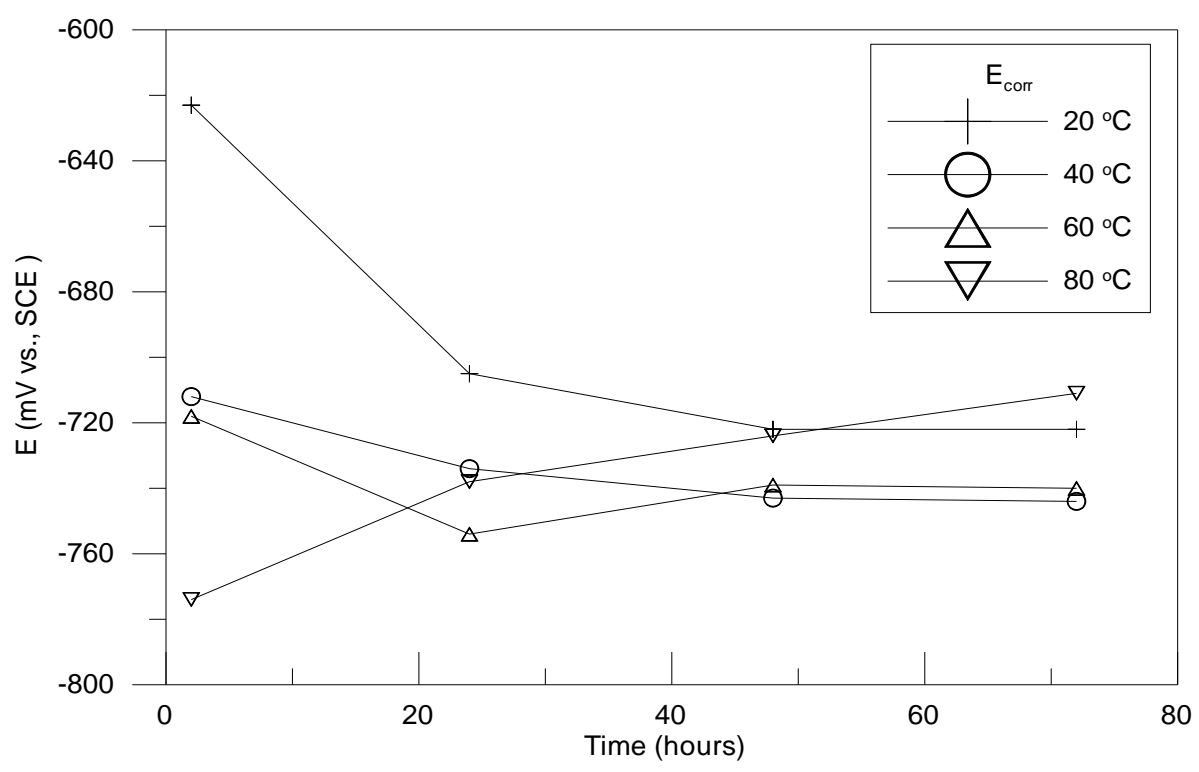

Fig.1. Time dependence of $\mathbf{E}_{\text {corr }}$ for MS exposed to AS at different temperatures. 

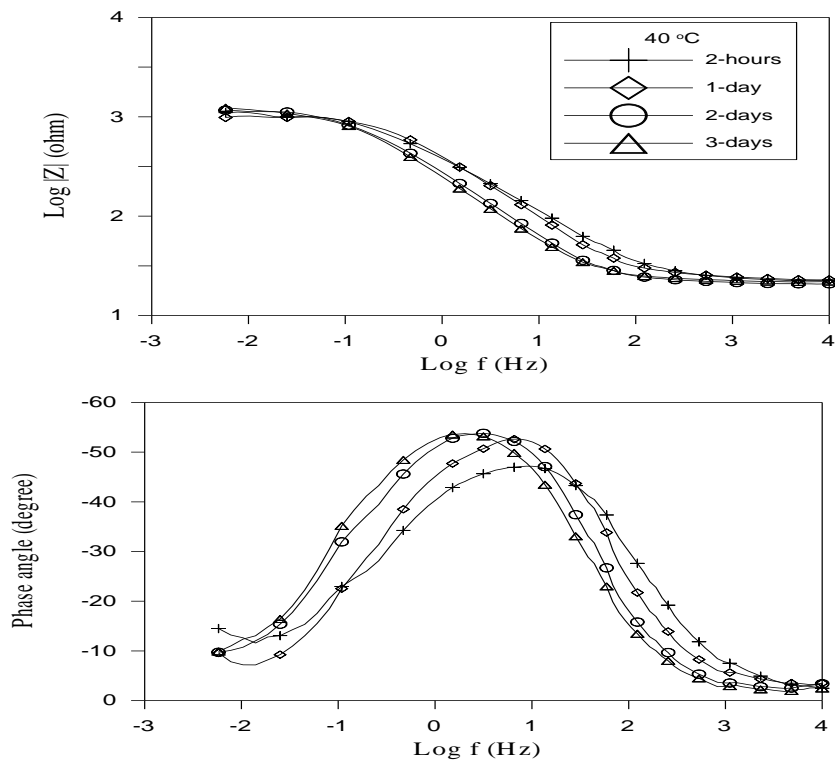

Fig.2. Bode plots for MS exposed to AS at $40{ }^{\circ} \mathrm{C}$.
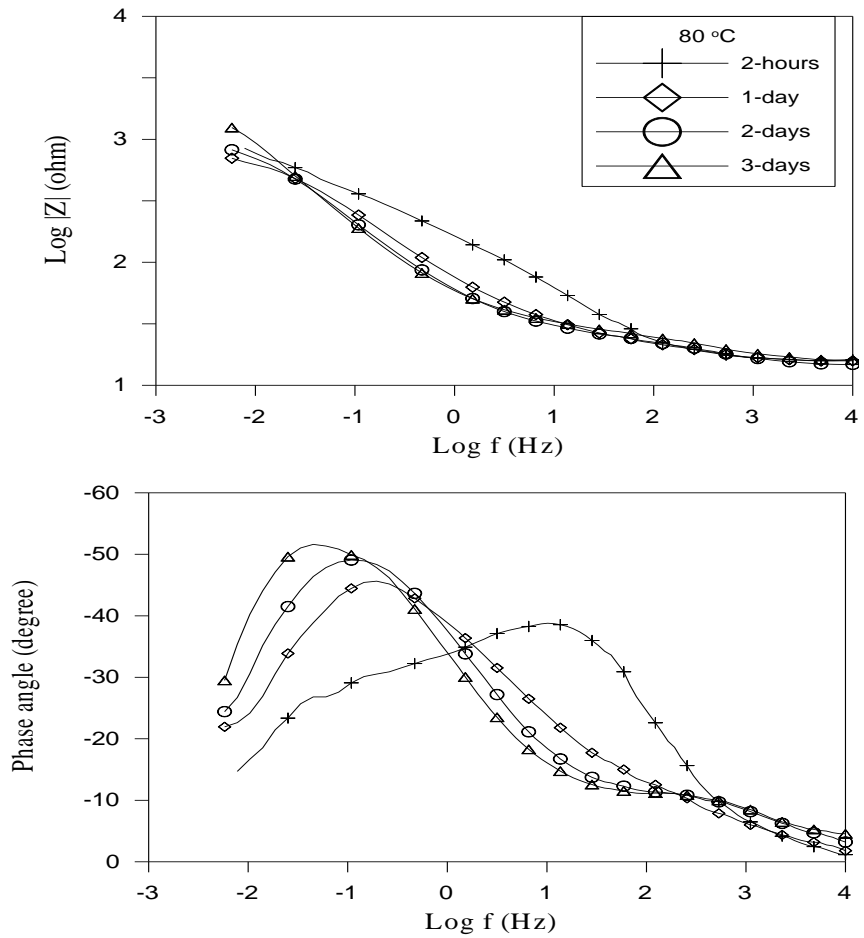

Fig.3. Bode plots for MS exposed to AS at $80{ }^{\circ} \mathrm{C}$. 

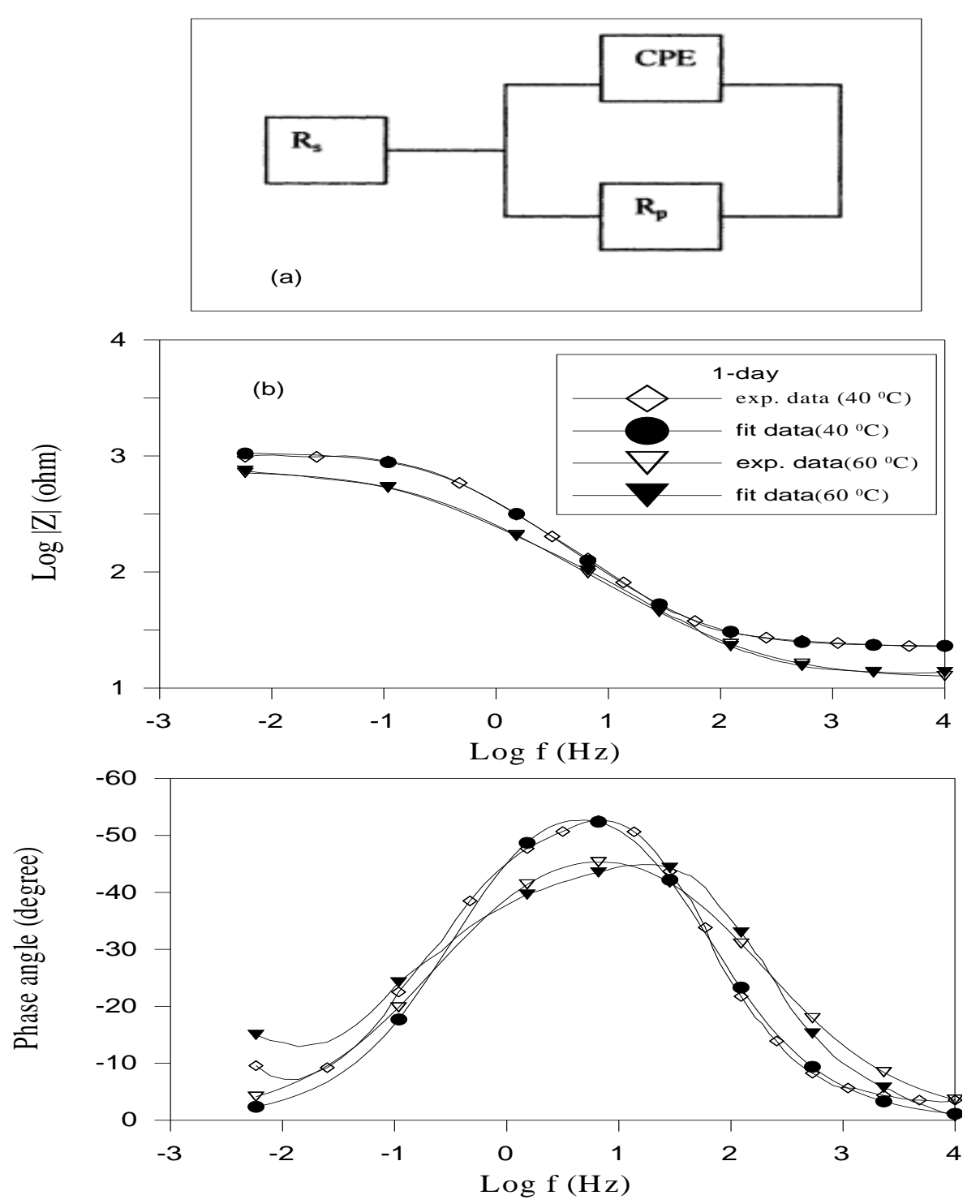

Fig.4. EC:

(a) one time constant model,

(b) Comparisons of experimental and fit data for MS exposed to AS after 1 day. 

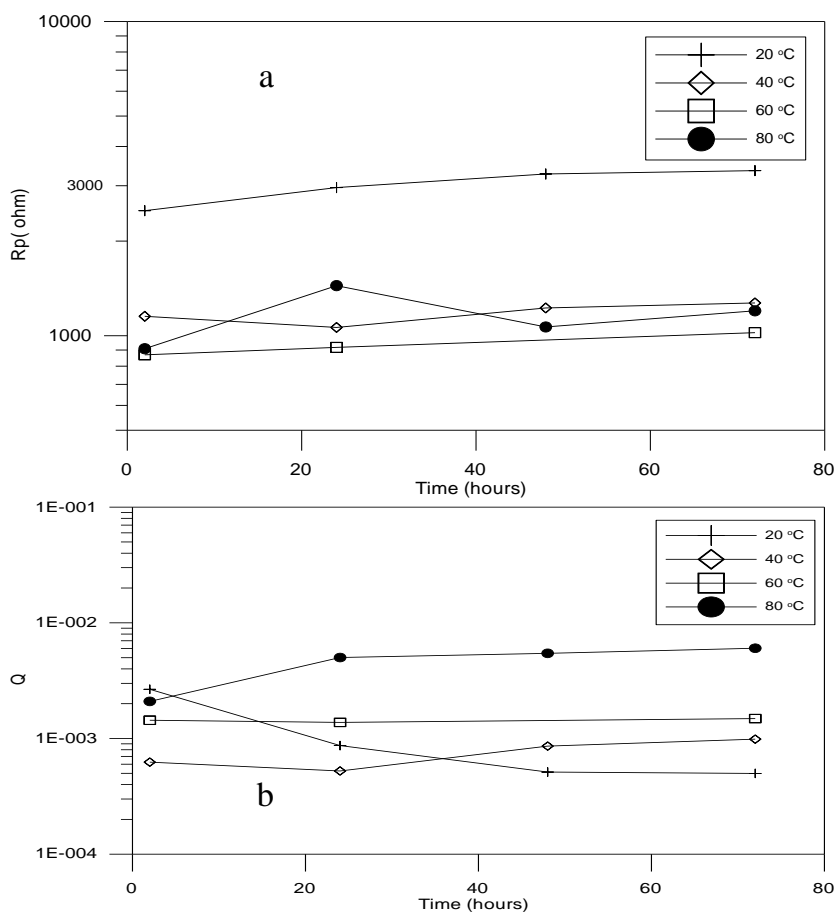

Fig. 5. Time dependence of (a) $R_{p}$, and (b) $Q$ for MS exposed to AS at different temperatures.
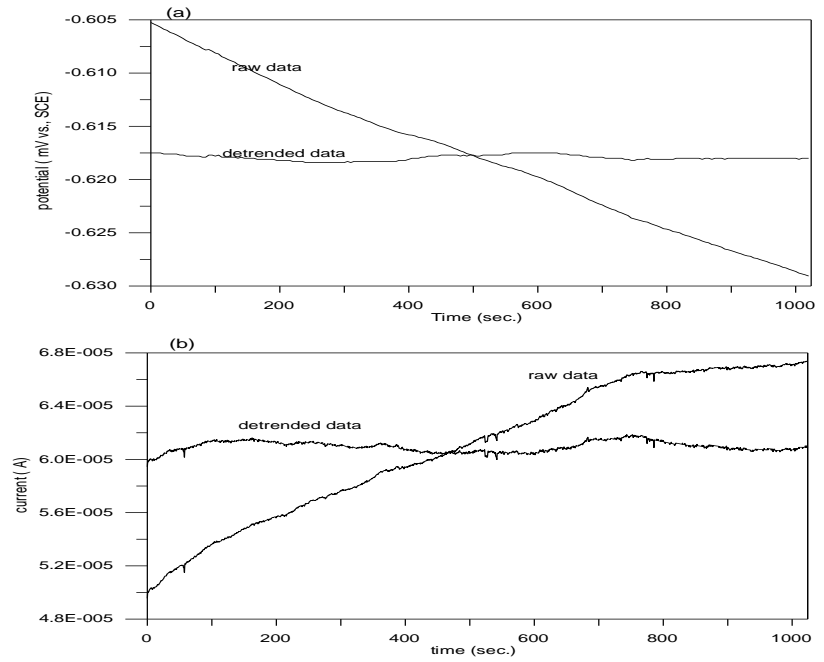

Fig.6. Noise potential (a) and noise current (b) fluctuations for MS exposed to AS after 2 hours before and after trend removal. 


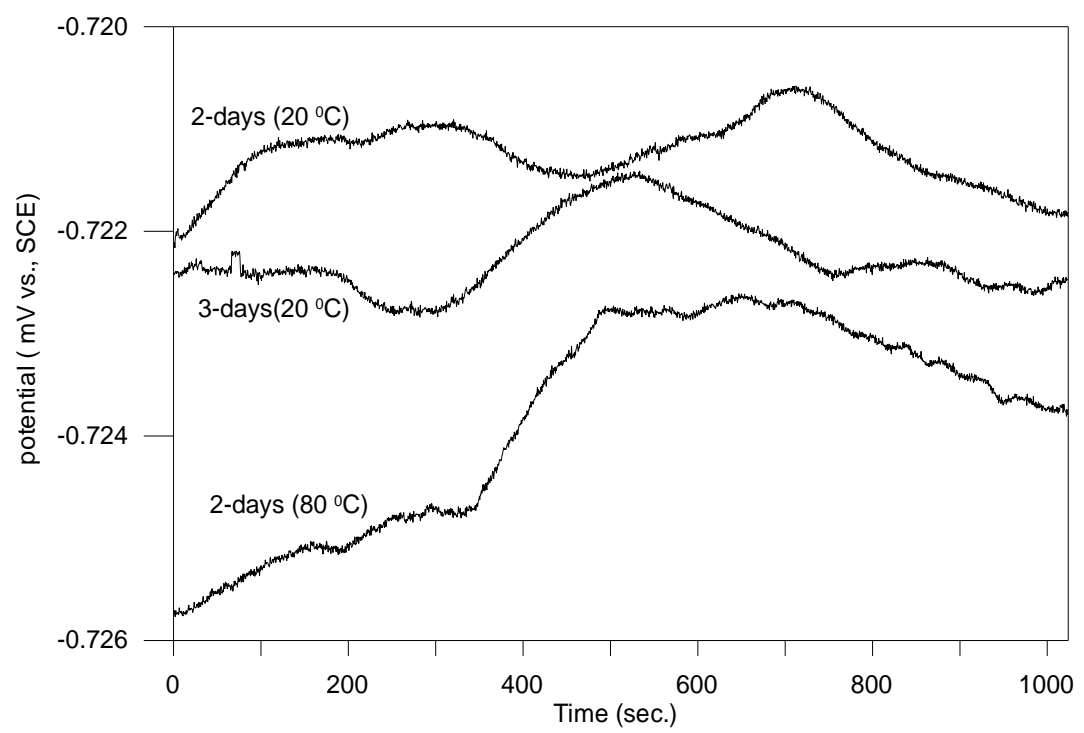

Fig.7. Noise potential fluctuations for MS exposed to AS after different immersion time and temperatures before trend removal.

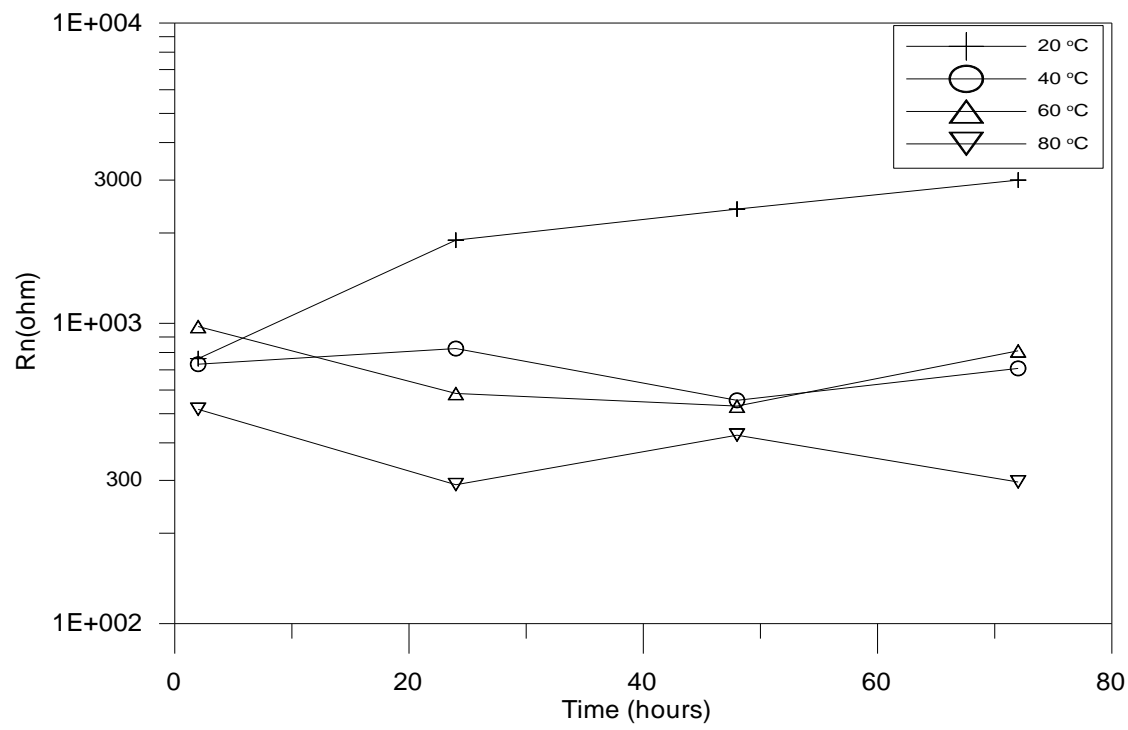

Fig.8. Time dependence of $R_{n}$ for MS exposed to AS at different temperatures. 


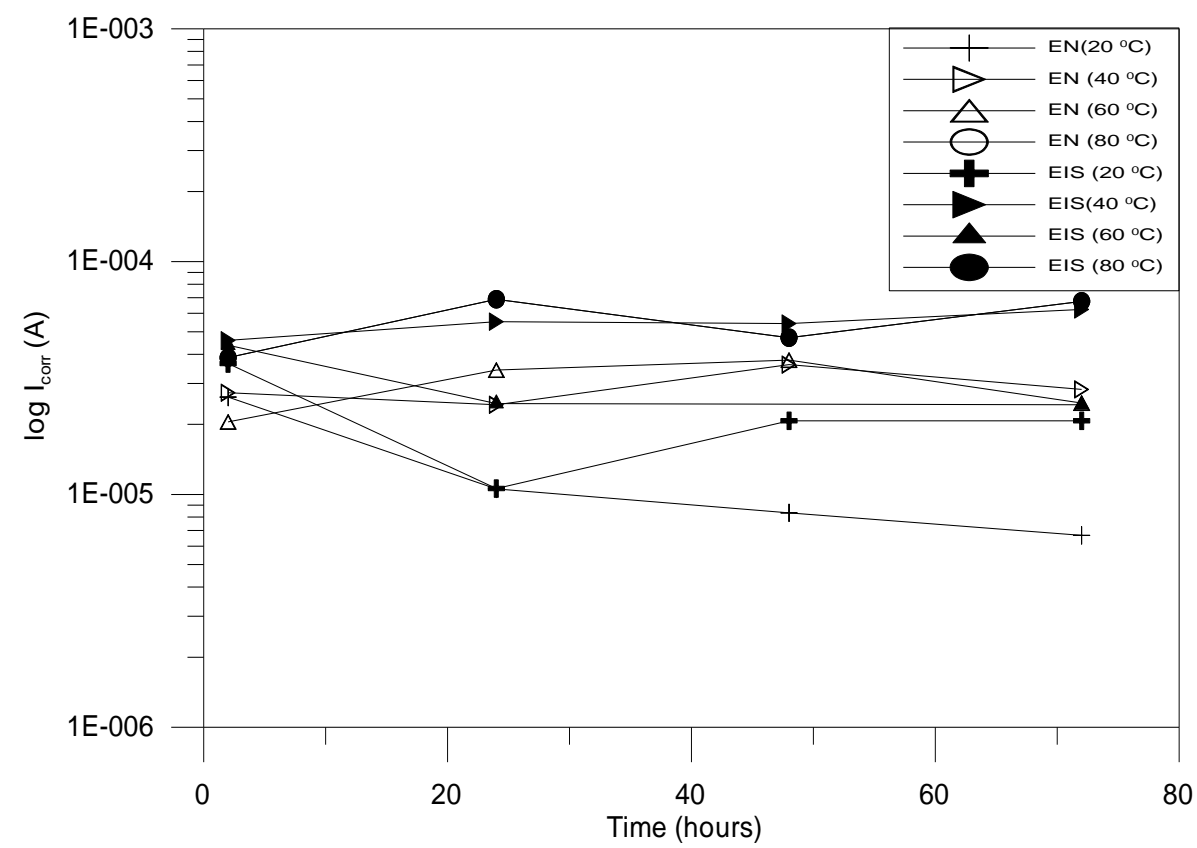

Fig. 9 Log $\left(I_{\text {corr }}\right)$ - time plots for MS exposed to AS at different temperatures.

\section{References}

1. A. M. BECCARIA, P. FIORDIPONTI AND G. MATRONGO, Corros. Sci. 29 (1989) 403.

2. K. A. CHANDLER, Marine and Offshore Corrosion, Butterworths, London (1988).

3. H. UHLIG, Corrosion handbook, pp 125-143, Wiley, New York, 1948.

4. Robert E Melchers, Corros. Sci. 45 (2003) 2609.

5. L. L. SHREIR, “Corrosion (Vol.1) ”pp3-5, Newnes-Butterworths, 1976.

6. J.C. HUDSON, Corrosion of bare iron and steel in seawater, J. Iron Steel Inst. (166) (1950)123.

7. U.R. EVANS, The Corrosion and Oxidation of Metals: Scientific Principles and Practical Applications, Edward Arnold (Publishers) Ltd., London, 1960.

8. S. ELBEIK, A. C. C. TSEUNG, A. L. MACKAY, Corros. Sci. 26 (1986) 669.

9. W. P. IVERSON, J Electrochem. Soc. 115 (1968) 617.

10. V. A. TYAGAI, Electrochim. Acta 16 (1971)1647.

11. V. A. TYAGAI, Elektrokhmiya 10 (1974) 3. 
12. D. A. EDEN, K. HLADKY, D. G. JOHN, J. L. Dawson, "Electrochemical Noise- Simultaneous Monitoring of Potential and Current Noise Signals from Corroding Electrodes," Corrosion 86 paper no. 274 (NACE).

13. A. ABAlle, A. BAUTiSta, U. BertocCI, F. HUET, “ The Measurement of Noise Resistance for Corrosion Application”, Corrosion 2000 paper no. 424 (NACE).

14. U. BERTOCCI, C. GABRIELLI, F. HUET, M. KEDDAM, J. Electrochem.Soc.144 (1997) 31.

15. F. MANSFELD, X. Xiao, Electrochem. Soc. 144 (1997) 2068.

16. J. R. KEARNS, J. R. SCULLY, P. R. ROBERGE, D. L. REICHERT and J. L. Dawson, eds., Electrochemical Noise Measurement for Corrosion Application, ASTM STP 1227 (West Conshohocken, PA : American Society for Testing and Materials, (1996)).

17. F. MANSFELD, Z. Sun, Corrosion, 55 (1999) 915.

18. F. MANSFELD, Z. SUN, C. H. HSU, A. Nagiub, Corros. Sci. 43 (2001)341.

19. A. NAGIUB, F. MANSFELD Corros. Sci. 43 (2001)2001.

20. G. HERNANDEZ, V. KUCERA, D. THIERRY, A. PEDERSEN, M. HERMANSSON, Corrosion 50 (1994) 603.

21. B. A. BOUKAMP, Equivalent Circuit, Princeton Applied Research Corporation, Princeton, NJ, 1990.

22. F. B. GROWCOCK, J.H. JASINSKI, J. Electrochem. Soc. 136 (1989) 2310.

23. Z. STOINOV, Electrochim. Acta 35 (1990) 1493.

24. W. H. MULDER, J.H. Sluyters, Electrochim. Acta 33 (1988) 303.

25. U. RAMMELT, G. REINHARD, Electrochim. Acta, 35 (1990)1045.

26. Z. STOYNOV, B. Savova-Stoynova, Commun. Dep. Chem. Bulg. Acad. Sci. 23 (1990) 279.

27. U. RAMMELT, G. REINHART, Corros. Sci. 27 (1987) 373.

28. A. NAGIUB, F. MANSFELD Corros. Sci. 43 (2001) 2147.

29. A.P. YADAV , A. NISHIKATA, T. Tsuru, Corros. Sci. 46 (2004) 169.

30. A. BONNEL, F. DABOSI, C. DESLOUIS, M. DUPART, M. KEDDAM, B. TRIBOLLET, J. Electrochem. Soc. 130 (1983) 753.

31. C. GABRIELLI, F. HUET, M. KEDDAM, Electrochim. Acta 31 (1986) 1025.

32. U. BERTOCCI, J. FRYDMAN, C. GABRIELli, F. HUET, M. KEDDAM, J. Electrochem. Soc. 145 (1999) 915.

33. U. BERTOCCI, F. HUET, R. P. NOGUEIRA, P. ROUSSEAU, Corrosion 58 (2002) 337. 